\title{
Tensile, Fatigue and Vibration Damping Characteristics of High- Performance Glass Fiber Reinforced Composites with Aligned MWNTs
}

\author{
Sasidhar Jangam, S. Raja, K. Hemachandra Reddy, Shijo Thomas
}

\begin{abstract}
In the present work multi-walled carbon nanotubes (MWNTs), the highly anisotropic, promising nanofillers used as additional structural reinforcement to improve the tensile, fatigue and damping capabilities of glass fiber reinforced composites (GFRP) for the Micro Air Vehicle (MAV) application. Further, the GFRP nanocomposites have been strengthened by making use of strong anisotropy of MWNT's by aligning them on each layer of GFRP laminate. GFRP nanocomposites have been prepared for very low weight percentage ( $0.5 \mathrm{wt} \%)$ of MWNT, with alignment and without alignment. The alignment has been done with the newly developed in-house electrode-fixture assembly, which can be scalable to any size. The result shows that the alignment of MWNTs on GFRP lamina has a significant effect over GFRP lamina without MWNT alignment and the neat GFRP (without any nano reinforcements) without sacrificing any of the mechanical properties.
\end{abstract}

Keywords: Multi-Walled Carbon Nanotubes (MWNTs), Glass fiber reinforced composites, Nanotube Alignment, Fatigue, Structural Damping.

\section{INTRODUCTION}

$\mathrm{T}$ he invention of composites has given a big boom to the manufacturing industries. Owing to their excellent material properties the Composites have become very popular and widely used in many industries. Especially in early 20th century a new era has started after the discovery of synthetic resins (polymers) and in the middle of $20^{\text {th }}$ century the composites evolved as durable and reliable structural elements reinforced with artificial fibers (glass, carbon,

Revised Manuscript Received on February 20, 2020.

* Correspondence Author

Sasidhar Jangam*, Department of Mechanical \& Automobile Engineering, Christ University, Bangalore 560074, India. E-mail: sasidhar.jangam@gmail.com

S. Raja, Structural Technologies Division, CSIR National Aerospace Laboratories, Bangalore 560017, India. Email: raja@nal.res.in

K. Hemachandra Reddy, Department of Mechanical Engineering, Jawaharlal Nehru Technological University, Anantapur 515002, India. E-mail: konireddy@gmail.com

Shijo Thomas, Department of Mechanical \& Automobile Engineering, Christ University, Bangalore 560074, India. E-mail: shijo.thomas@ christuniversity.in

(C) The Authors. Published by Blue Eyes Intelligence Engineering and Sciences Publication (BEIESP). This is an open access article under the CC BY-NC-ND license (http://creativecommons.org/licenses/by-nc-nd/4.0/) aramid fibers), since then the applications of composites traced in every possible sector like automotive, aerospace, marine, defence, biomedical, etc. Further, these artificial fibers can able to offer very high performance when combined with polymers rather than metal alloys or ceramics [1-4]. Among many artificial fibers especially glass fiber reinforced polymer composites (GFRPs) and carbon firber reinforced polymer composites (CFRPs) are very popular and widely accepted for the commercial applications because of its high strength and stiffness, large fracture toughness and strength, huge fatigue capacities, low density and ease of fabrication [5-6]. Apart from the superior mechanical properties, GFRPs and CFRPs exhibit low cost to performance ratio when compared with Kevlar and aramid reinforced polymer composites. This low cost to performance ratio makes the GFRPs and CFRPs to use extensively in manufacturing many aircraft parts of the new generation and indigenously developed Indian aircrafts like Tejas, Saras, Hansa, etc.

However, the performance of many aircraft parts, including wings, ailerons, flaps, spoilers and rudders severely get affected due to the vibrations despite of their superior mechanical properties obtained from the GFRPs or CFRPs. In general, the materials with huge stiffness exhibits low damping, which leads to a serious issue when the aircraft structures have preexisting micro-cracks or developed during the operation results in fatigue failure due to vibrations [7-11]. This high stiffness and low damping ability limit the extensive usage of GFRPs and CFRPs in the aircraft industry. Many attempts were made to enhance the damping ability of FRPs without sacrificing their mechanical properties, but no significant improvement has been recorded.

After Iijima developed coaxial tube structures made of carbon at nano dimension [12], the scientific community has devoted significant efforts to enhance the composite properties by using CNTs as promising structural reinforcement [13-14]. The carbon nanotubes exhibit excellent mechanical, thermal and electrical properties due to its 1D structure. CNTs gives good results, especially with the polymers. Further, the CNTs offer a very good damping ability when used as reinforcements in the polymers due to its large surface and interfacial area, and weak interfacial adhesion which causes dissipation of more energy at the CNT and polymer matrix interface. 
The mechanism behind this phenomenal improvement of damping at the interface of nano reinforcements and the polymer matrix is known as the "stick-slip" mechanism [15]. If the force is applied on the nanocomposites, the CNTs and the polymer matrix will start deforming together.

Once the external load exceeds the threshold value, the CNTs stop deforming while the polymer matrix continues which makes the CNTs slip at the polymer matrix boundaries results in energy dissipation [16]. Further, the interfacial energy dissipation capacity depends on the amount of force applied and the rate of applied force. Usually, the dissipation energy is directly proportional to the amount of force applied and its rate of application.

Most previous studies were related to improving the mechanical, vibration damping and electrical properties of epoxy-based nanocomposites and fiber reinforced nanocomposites with CNTs distributed randomly in their matrix, but the influence of CNT alignment was not much studied. In our previous work [13-14], we have studied the effect of CNT alignment on fatigue and vibration damping in epoxy-based nanocomposites. Now in our present work, we studied the effects of CNT alignment on tensile, fatigue and vibration damping characteristics of CNT/GFRP hybrid composites. The CNT/GFRP hybrid composites are produced using hand- layup technique. CNT reinforced resin was used as a composite matrix and CNTs are aligned or oriented using a special in-house developed alignment setup which works on the parallel electrode concept. The tensile, fatigue and vibration damping tests are conducted as per the respective ASTM standards.

\section{MATERIALS AND EXPERIMENTAL METHODOLOGY}

\section{A. Materials}

The nanoparticles used in this study were Multiwall
Carbon Nanotubes (MWNT), purchased from Nano shell, USA. The MWNTs were produced by chemical vapor deposition (CVD) technique and functionalized with acid for better dispersion. As per the supplier's specification, the physical dimensions of MWNTs were as follows: diameter ranged between 10 - $20 \mathrm{~nm}$ and length ranged between 10 $15 \mathrm{~mm}$. Glass fiber, bi-axial mat (7 mills) was used as fiber reinforcement, and it was supplied by Arun fabrics, Bangalore. The Diglycidyl ether bisphenol A (DGEBA) commercial structural thermosetting resin, was used as matrix system and Triethylenetetramine (TETA) was used as curing agent/hardener for preparation of fiber reinforced composite specimen, and these were procured from Sigma-Aldrich Chemicals, USA. The DGEBA and TETA were employed with a mix ratio of $100: 12$, respectively, by weight [17]

\section{B. Preparation of Specimens}

The MWNTs procured were added to the epoxy resin without any chemical modification and manually mixed thoroughly about $5-10$ minutes, then the solution was sonicated for one hour to improve the quality of MWNT dispersion in the epoxy. During sonication, the nanomixture temperature was continuously monitored and maintained low to avoid the issues arising due to overheating. The MWNT/epoxy mixture was then degassed in a vacuum oven for 10 minutes to eliminate the entrapped air, and further curing agent/hardener was added with a weight ratio to epoxy of 12:100.

After a thorough manual stirring for about 10-15 minutes, the homogeneous nanomixture was used to wet the glass fabric layer. The wetting of a glass fabric layer was done in the wetting zone with the help of a soft roller. The wetted layer was then gone through the sizing zone where the excess amount of resin was squeezed out by sizing die. The glass fabric layer with optimum resin then passed through distance and connected to the DC electric field. The speed of the layer

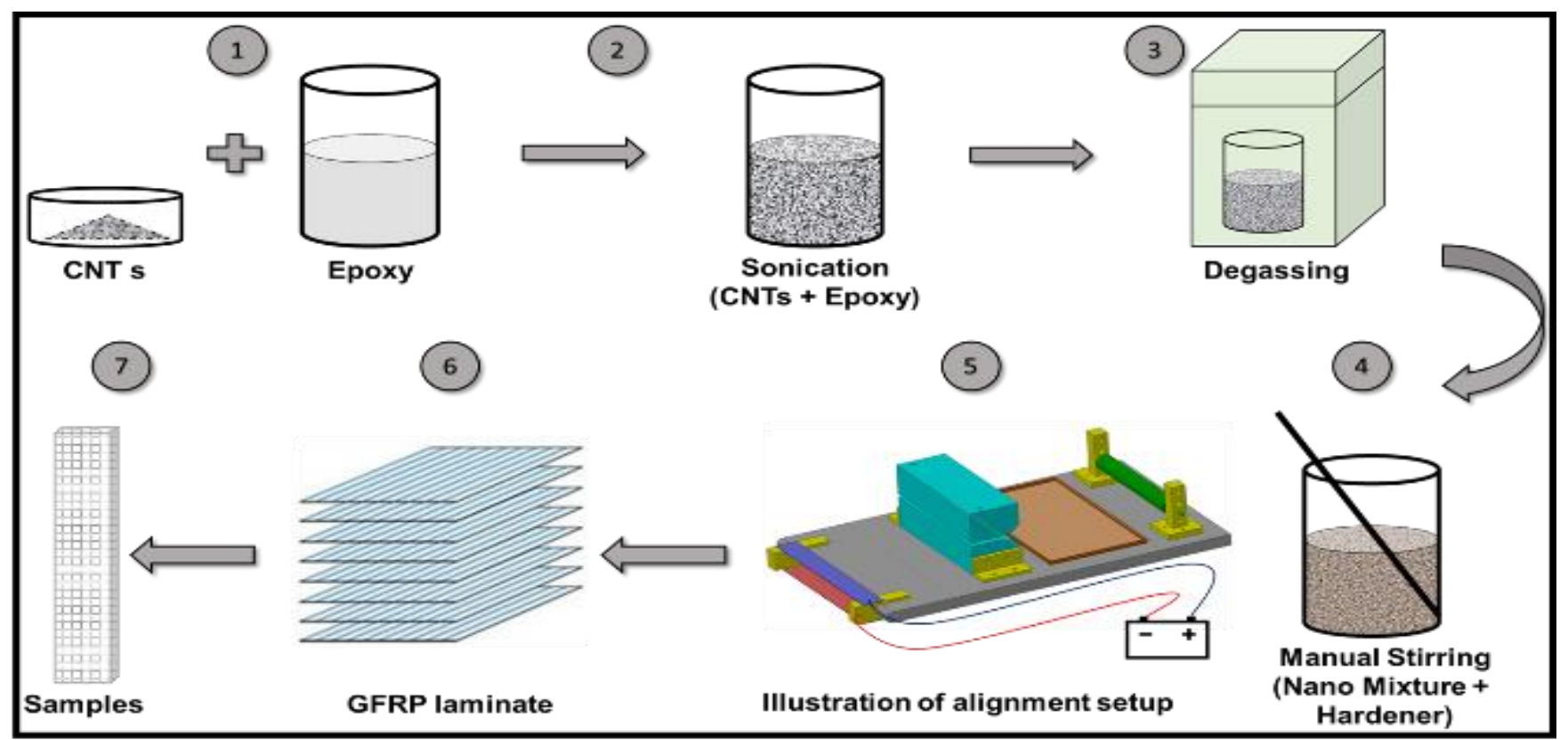

Fig.1. Schematic of apparatus for CNT dispersion and alignment of glass fiber reinforced nanocomposite fabrication 

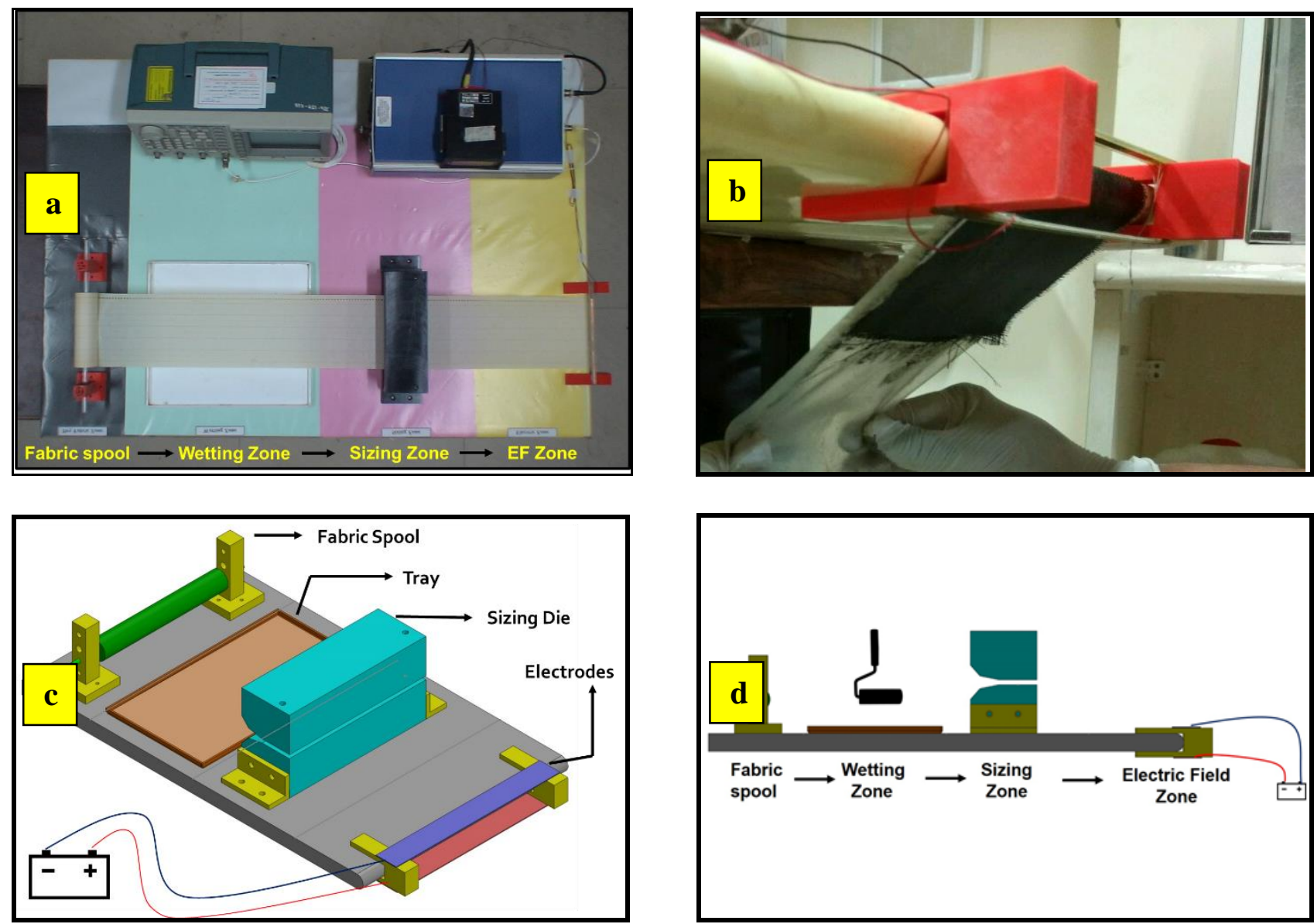

Fig. 2. Inhouse developed CNT dispersion and alignment fabrication setup (a) Fabrication setup of fiber reinforced composites with CNT alignment (b) Close view of electric field zone (c) CAD model of fabrication setup (d) Different zones of fabrication process

through the electric field zone was maintained constant $(1 \mathrm{~m} / \mathrm{min})$ in such a way that, the MWNTs will get sufficient time to react and align for the applied DC electric field. Once the alignment process was over the layers were stacked up to prepare a laminate. This laminate with aligned MWNTs was then allowed to cure for 24 hours at room temperature $\left(23 \pm 2{ }^{\circ} \mathrm{C}\right.$ ), and during the curing process, uniform pressure was applied on the laminate to obtain uniform thickness. The cured composite laminates were post cured for a high degree of polymerization at $50^{\circ} \mathrm{C}$ for $30 \mathrm{~min}, 70^{\circ} \mathrm{C}$ for $60 \mathrm{~min}$ and $85^{\circ} \mathrm{C}$ for $2 \mathrm{~h}$ in the oven. Fig. 1 shows the Schematic of apparatus for CNT dispersion and alignment of glass fiber reinforced nanocomposite fabrication.

In this current research work, glass fiber reinforced nanocomposites were prepared with low content of MWNTs ( $0.5 \mathrm{wt} \%)$ in the epoxy matrix with random and aligned CNT networks. For comparison purposes, the neat epoxy specimens (GFRP/NE) were also prepared along with the random oriented (GFRP/R0.5\%) and aligned (GFRP/A0.5\%) fiber reinforced nanocomposites. The composite laminate was made for a total of four layers. Fig. 2 shows the inhouse developed CNT dispersion and alignment fabrication setup and various stages of the fabrication process.

\section{Testing Procedure} reinforced nanocomposites to measure tensile strength, tensile strain (strain at break), and Young's modulus. The test specimen prepared were of rectangular geometry with the
The tensile tests were carried out on the glass fiber

dimensions of $100 \times 10.5 \times 0.7 \mathrm{~mm}^{3}$. The tensile tests were conducted on Instron E 3000 under position control with a constant pull rate of $0.5 \mathrm{~mm} / \mathrm{min}$ as per the ASTM D 3039. A clip type extensometer (Instron 2620-601) with a gauge length of $12.5 \mathrm{~mm}$ was used to measure the strain of the specimen. Data acquisition and processing was done by Blue hill $2^{\circledR}$ software to obtain the tensile properties. Fig. 3. shows the experimental setup and test specimens of tensile, fatigue, and dynamic mechanical analysis.

The cyclic fatigue tests were conducted in Instron Electro pulse 3000 under force control mode with test parameters: sinusoidal fixed cyclic frequency $\mathrm{f}=3 \mathrm{~Hz}$, stress ratio $\mathrm{R}=0.1$ $\left(\mathrm{R}=\sigma_{\min } / \sigma_{\max }\right)$ [2]. The cyclic frequency $3 \mathrm{~Hz}$ was so arrived after performing many trials in the frequency range of $1-3 \mathrm{~Hz}$. The fatigue tests were performed on each category of specimens either up to failure or 1 X105 cycles. Fig. 3. shows the experimental setup of fatigue tests.

The dynamic mechanical analysis was done to evaluate the material damping characteristics of the fiber reinforced nanocomposites. The DMA tests were conducted on Instron Electro Pulse 3000, with constant force amplitude, tensile tensile oscillation mode in the frequency range of $0-30 \mathrm{~Hz}$. The load corresponds to $0.05 \%$ of strain of simple tensile test was applied as load amplitude. The specimens were of rectangular geometry with the dimensions of $100 \times 10.5 \times 0.7$ $\mathrm{mm}^{3}$. 
Tensile, Fatigue and Vibration Damping Characteristics of High- Performance Glass Fiber Reinforced Composites with Aligned MWNTs

Clip type dynamic extensometer (Instron 2620-601) was attached to the specimen to capture the dynamic response of the specimen under the time and frequency dependent loading. The data acquisition and processing were done by wave matrix software to obtain storage modulus,

loss modulus, and damping factor values. Fig. 3 shows the experimental setup of DMA.

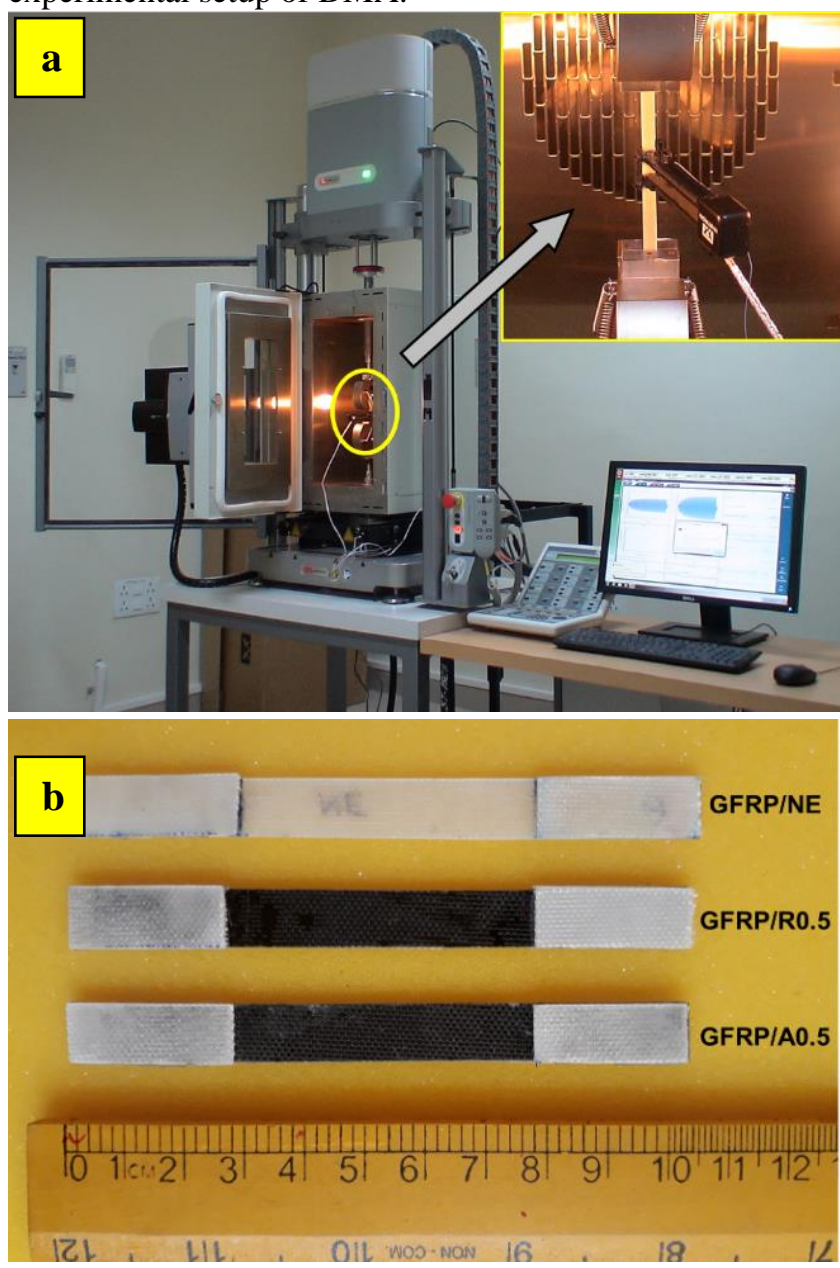

Fig.3. (a) Test setup of tensile, fatigue, and dynamic mechanical analysis (b) Test specimens of the tensile, fatigue and dynamic mechanical analysis

Impulse vibration tests were performed on the fiber reinforced nanocomposite beam samples to find the natural frequencies $\left(f_{n}\right)$ and damping ratios $(\zeta)$. The nanocomposite beams were of rectangular geometry with the dimension 250 x 25 x $1 \mathrm{~mm}^{3}$ were used as cantilever beams. An impulse hammer (PCB 086E80) was used to give initial excitation, and a uniaxial accelerometer (Dytran 352C22) was used to collect the response through LMS MOBILE SCADAS SCM01. LMS test lab was used to acquire and process the vibration data. The half-power bandwidth technique was adapted to calculate the fundamental frequencies $\left(f_{n}\right)$ and damping ratios $(\zeta)$ from the corresponding FRF's (Frequency Response Function). Fig. 4 shows the experimental test setup of Impulse vibration test.

Microscopic analysis was done to check the quality of dispersion and the alignment of MWNTs on the GFRP layer. Besides to this analysis, the fracture investigation and analysis was also done by examining the fractured surfaces. Field emission scanning electron microscope (ZEISS supra 40VP) was used for microscopic analysis.

\section{RESULTS AND DISCUSSION}

\section{A. Tensile Test}

The Fig. 5 shows the typical stress-strain curves of glass
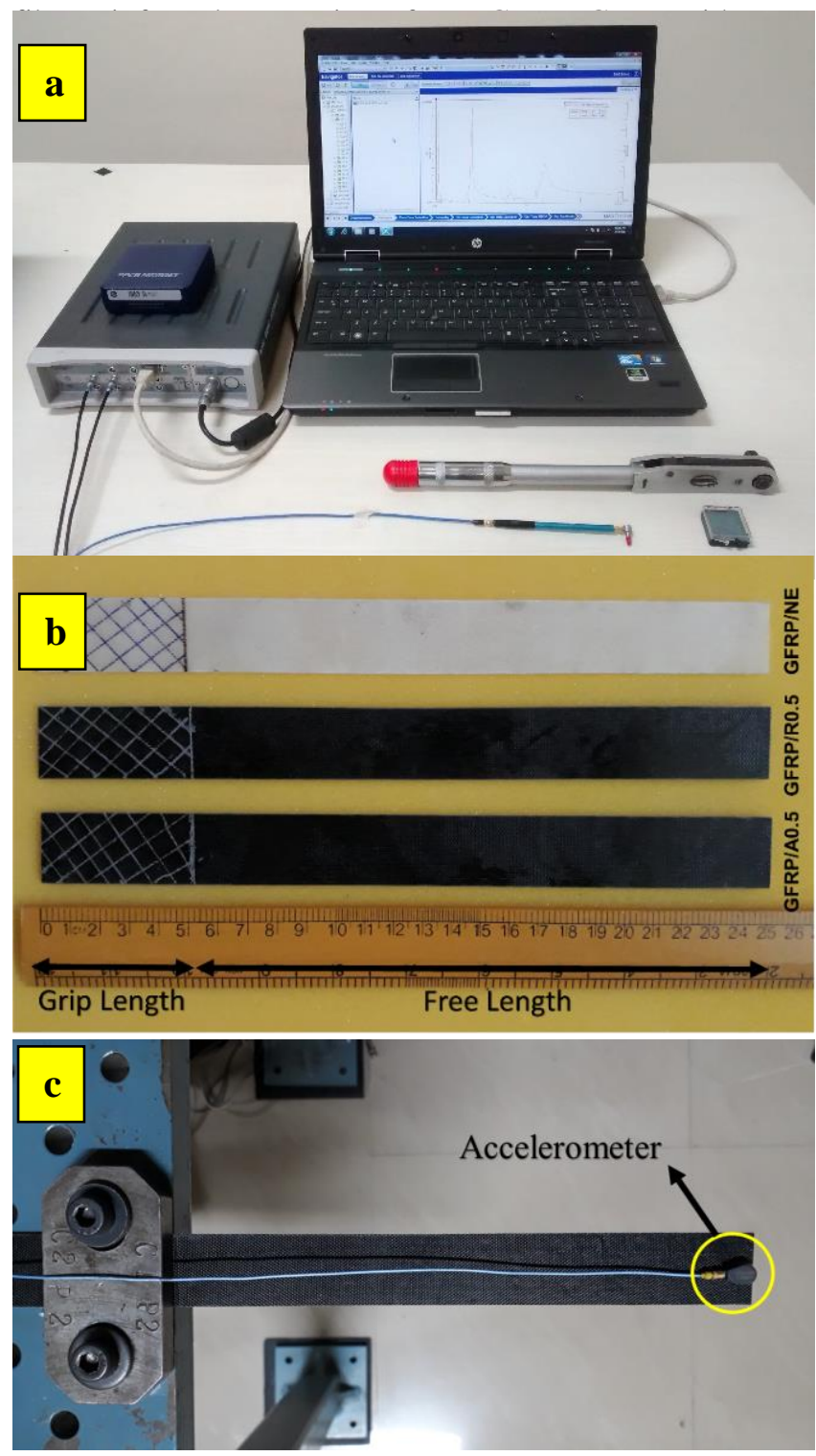

Fig.4. Experimental test setup of Impulse vibration test (a) LMS data acquisitions system, (b) Vibration test specimens of glass

fiber reinforced nanocomposite, (c) Experimental setup of Impulse vibration test

random MWNT and GFRP with aligned MWNTs. The average and standard deviation values of the tensile modulus $(E)$, ultimate tensile strength $\left(\sigma_{U}\right)$ and ultimate tensile strain $\left(\varepsilon_{U}\right)$ are listed in the Table.1. It was observed that the addition of MWNTs to the GFRPs improved the tensile modulus compared to the neat GFRP. The random MWNT networks in the GFRP has shown nearly 10\% improvement over neat GFRP. Whereas, for the same MWNT loading the aligned MWNT networks in the GFRP has shown $26 \%$ over neat GFRP and 14\% over GFRP with random networks. It was also observed that there is a remarkable effect on ultimate tensile strain due to MWNTs inclusion and alignment. However, considering the low weight percentage of inclusion, the differences may be small to be considered statistically significant. 
It is worth noticing that, the tensile strength was very similar for all the specimen categories examined. Another interesting observation was that the toughness (area under the stress-strain curve) of both random and aligned networks slightly increased with respect to the neat GFRP due to the increased

Table. 1: The tensile properties of the glass fiber reinforced nanocomposites

\begin{tabular}{cccc}
\hline $\begin{array}{c}\text { Specimen } \\
\text { type }\end{array}$ & $\begin{array}{c}\text { Tensile } \\
\text { Modulus } \\
-\mathbf{E}(\mathbf{G P a})\end{array}$ & $\begin{array}{c}\text { Ultimate Tensile } \\
\text { Strength }-\boldsymbol{\sigma U} \\
\mathbf{( M P a )}\end{array}$ & $\begin{array}{c}\text { Ultimate Tensile } \\
\text { Strain }-\mathbf{E U}(\%)\end{array}$ \\
\hline GFRP/NE & $15.42 \pm 1.39$ & $219.24 \pm 12.04$ & $1.82 \pm 0.36$ \\
GFRP/R0.5 & $17.08 \pm 1.16$ & $217.54 \pm 10.75$ & $2.30 \pm 0.65$ \\
GFRP/A0.5 & $19.46 \pm 0.97$ & $216.73 \pm 13.01$ & $2.36 \pm 0.75$ \\
\hline
\end{tabular}

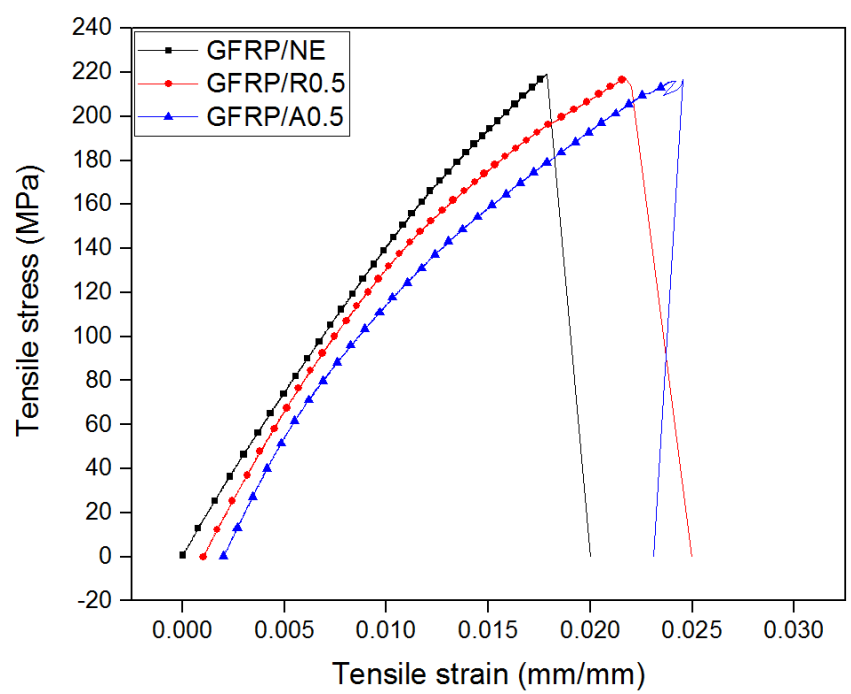

Fig. 5. stress-strain curve of glass fiber reinforced nanocomposites

ultimate tensile strain. Further, the aligned MWNT networks have recorded little higher toughness than the random MWNT networks. This indicates that the inclusion and the alignment of MWNTs have significant improvement in enhancing the stiffness and toughness of glass fiber reinforced nanocomposites.

\section{B. Fatigue Test}

The fatigue tests have been done to investigate the effect of MWNT alignment on fatigue behavior of glass fiber reinforced nanocomposites. The tensile fatigue tests were conducted under tension- tension mode with stress ratio (R) 0.1 and constant amplitude. The experimental fatigue data was used to fit the S-N curves by Basquin's equation. Fig. 6 (a) shows the S-N curves of the specimen tested.

$$
\sigma_{\max }=\sigma_{f}\left(N_{f}\right)^{b}
$$

Where of is the fatigue strength coefficient (FSC), which is a direct measure of fatigue life, $\mathrm{N}_{\mathrm{f}}$ is the number of cycles for failure and $\mathrm{b}$ is the fatigue strength exponent (FSE). Table. 2 gives the values of FSC and FSE. From the Table. 2, it is very clear that the addition of MWNTs to the GFRPs has improved the FSC value than the neat GFRP which clearly indicates that the MWNTs are favorable for enhancing the fatigue life provided with proper dispersion. Further, the alignment of MWNTs showed moderate improvement (7\%) over neat GFRP and marginal improvement $(0.5 \%)$ over random networks was observed. Fig. 6 (b) shows the bar graph of FSC for the various specimen tested.

Table. 2. Fatigue properties of the nanocomposites.

\begin{tabular}{ccc}
\hline $\begin{array}{c}\text { Specimen } \\
\text { type }\end{array}$ & $\begin{array}{c}\text { Fatigue Strength } \\
\text { Coefficient - FSC (MPa) }\end{array}$ & $\begin{array}{c}\text { Fatigue Strength } \\
\text { Exponent (FSE) }\end{array}$ \\
\hline GFRP/NE & $413.37381 \pm 32.25051$ & $-0.1282 \pm 0.01046$ \\
GFRP/R0.5 & $443.18663 \pm 29.33274$ & $-0.1321 \pm 0.00854$ \\
GFRP/A0.5 & $445.30639 \pm 24.64394$ & $-0.1300 \pm 0.00701$ \\
\hline
\end{tabular}
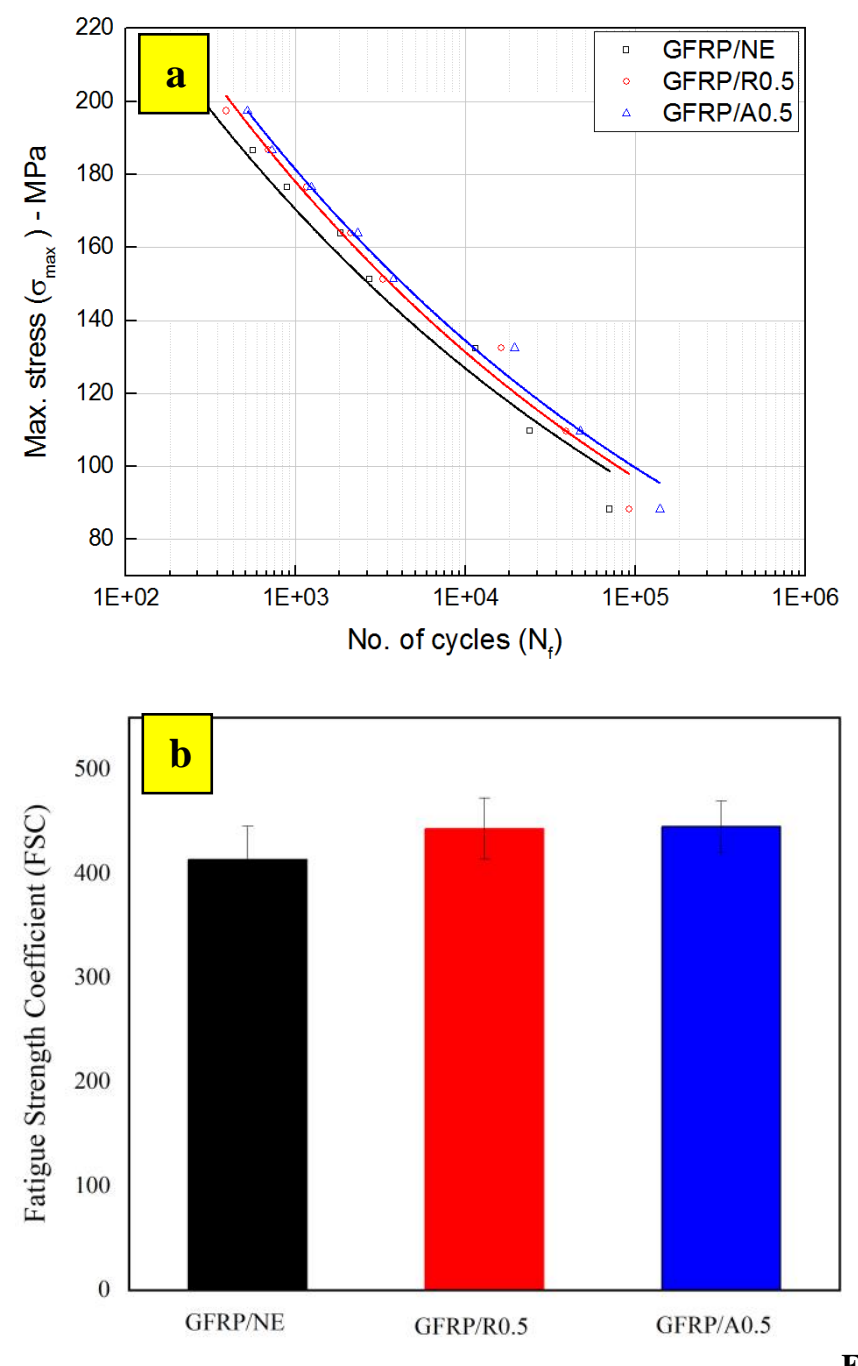

ig.6. (a) S-N curve (b) Bar graph of Fatigue Strength Coefficient (FSC).

\section{Dynamic Mechanical Analysis}

The material damping of MWNT reinforced (random and aligned) glass finer reinforced composites has been presented in terms of tan(delta) curves in Fig. 7 (a). It can be clearly seen that all the three categories of the specimen have shown similar damping trend in the frequency range of 1-30 Hz. For ease of analysis, the graph has divided into two portions; portion I (1-8 Hz) and portion II (8-30 Hz). In the portion I, the damping was increasing continuously with increase in the frequency up to $8 \mathrm{~Hz}$,

Published By:

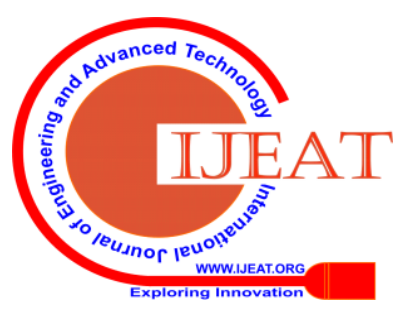



with Aligned MWNTs

which is due to the fact that at lesser frequencies the material system will have enough time to respond and stabilize for the applied load/stress. So, the damping keeps on changes until it stabilizes. In the portion II, the damping has a decreasing trend till $30 \mathrm{~Hz}$ with a constant slope. The material system will lose its damping capability as the frequency increases, and the fact behind this phenomenon is; as the frequency increases the system will be getting lesser time to react and offer some resistance to the applied forces/stress. It can be clearly seen that the addition of MWNTs has shown a marginal improvement in material damping over neat GFRP. Further, the alignment of MWNTs along the longitudinal axis for the same percentage of loading has shown significant improvement in damping over neat GFRP and GFRP with random MWNT networks. It was also observed that all the three specimen categories had shown small peaks at $11 \mathrm{~Hz}$ and $15 \mathrm{~Hz}$, and the reason behind these peaks was that one of the test machine components frequency was matching with the operational frequency of the test machine.

Fig. 7 (b) shows the storage modulus of glass fiber reinforced nanocomposites. Similar to the tan(delta) curves, all the three categories of the specimen have followed the same trend in the $0-30 \mathrm{~Hz}$ frequency range. It was observed that all the three storage modulus curves have a very little positive slope over the frequency range $0-30 \mathrm{~Hz}$ except at the very beginning stage of the curves, i.e. $0-2 \mathrm{~Hz}$. The main reason for the negative slope in the $0-2 \mathrm{~Hz}$ frequency range was that the DMA machine would have more inertia at the
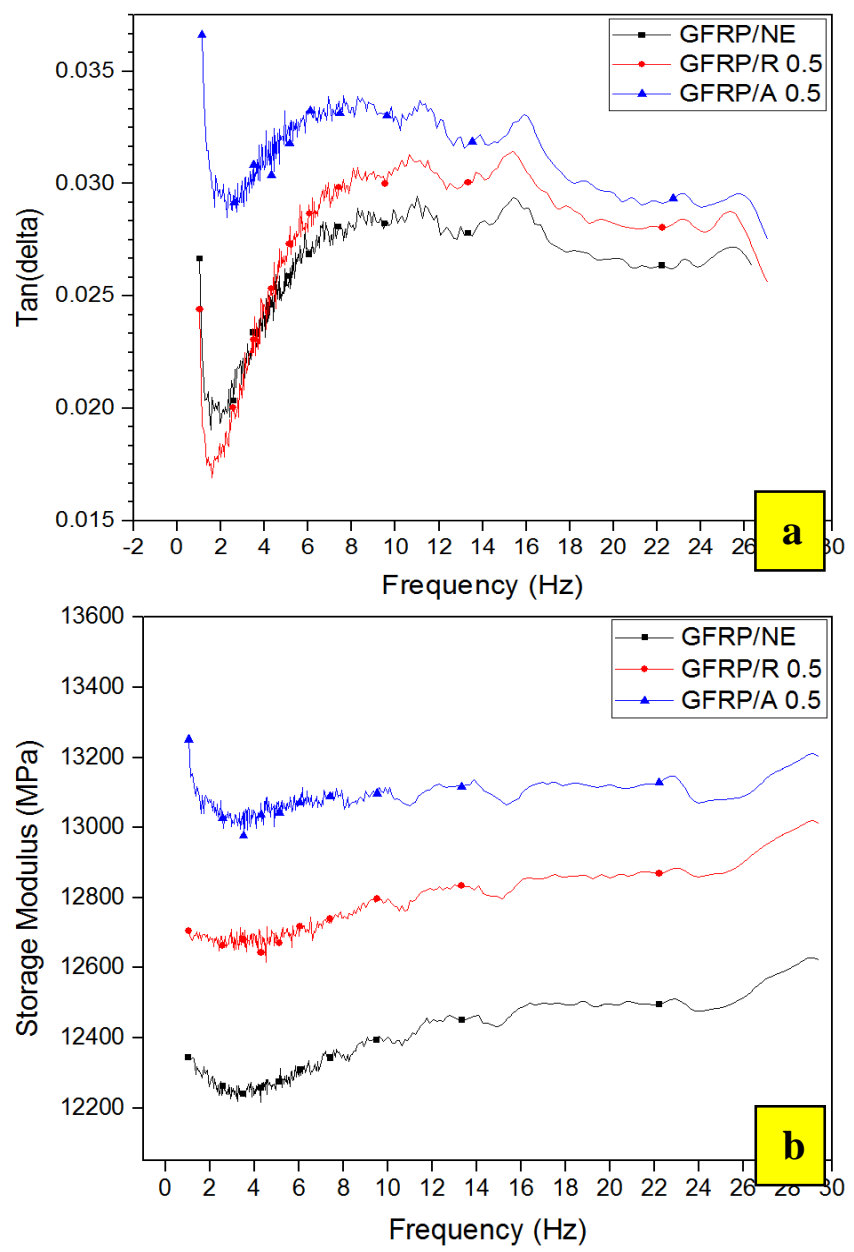

Fig.7. DMA curves of fiber reinforced nanocomposites (a) tan(delta) curves (b) storage modulus curves

beginning and it will take some time to reach the given amplitude and frequency. It was noteworthy that there was a sudden drop in storage modulus at the frequencies $11 \mathrm{~Hz}$ and $15 \mathrm{~Hz}$ which was due to the resonance. The addition of MWNTs and the alignment of MWNTs for a given wt.\% has a remarkable improvement in storage modulus.

From the DMA test, it is very clear that the addition of MWNTs has shown significant improvement in material damping as well as storage modulus. On top of that, the aligning of MWNTs in the longitudinal axis has improved the key material properties without sacrificing other material properties

\section{Flexural Vibration Test}

The flexural vibration test was done to estimate the damping ratio (structural damping) of GFRP with and without MWNT alignment. The Fig. 8 shows the FRF of all the three categories of the specimen. It can be clearly seen that the first three natural frequencies of all the three categories of specimen were same. It was observed that in the frequency bandwidth of $0-100 \mathrm{~Hz}$ all the peaks were sharp except the third peak which may be due to the insufficient energy to excite that particular mode at that frequency. The damping ratios which were calculated using the $3 \mathrm{db}$ method at the first natural frequency were compared to study the effect of MWNTs random and aligned dispersion behavior. From the Table 3, it is very clear that the damping ratio of both random and aligned networks have shown improvement over neat GFRP, but the improvement was marginal.

Table. 3. Fundamental frequencies $\left(f_{n}\right)$ and damping ratios $(\zeta)$ of glass fiber reinforced nanocomposites

\begin{tabular}{ccc}
\hline $\begin{array}{c}\text { Specimen } \\
\text { type }\end{array}$ & $\begin{array}{c}\text { Fundamental } \\
\text { Frequency }(\mathbf{H z})\end{array}$ & $\begin{array}{c}\text { Damping } \\
\text { Ratio }(\zeta)\end{array}$ \\
\hline GFRP/NE & 10.5 & 2.52 \\
GFRP/R0.5 & 10.5 & 2.81 \\
GFRP/A0.5 & 10.5 & 2.97 \\
\hline
\end{tabular}

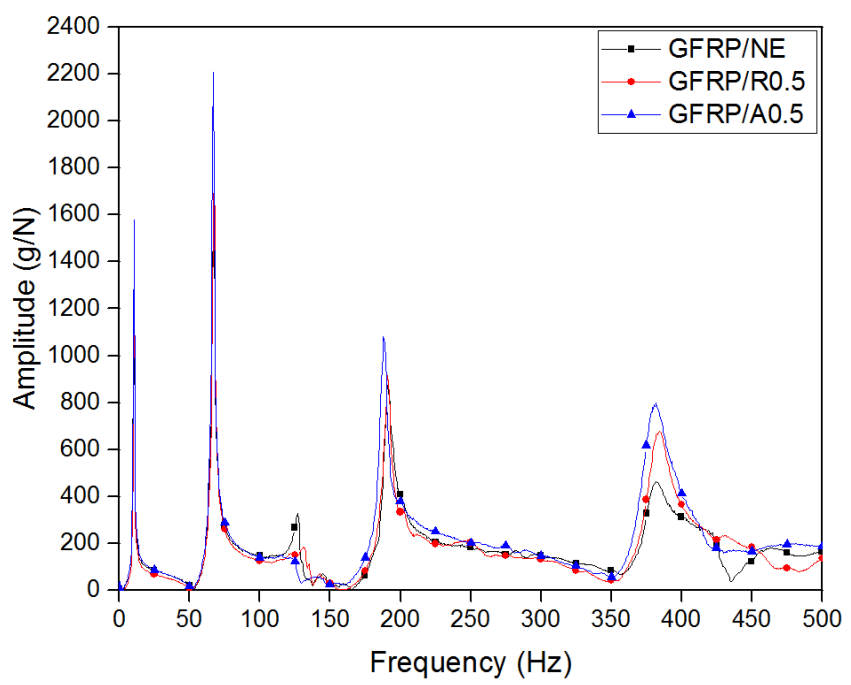

Fig. 8. FRF of glass fiber reinforced nanocomposites 
It was found that a moderate enhancement in the damping ratio is observed with the random MWNT networks than the neat GFRP. Whereas, the aligned MWNT networks have shown marginal improvement (5\%) over random networks; however, the improvement was significant (11\%) when compared with neat GFRP. Similar kind of behavior has also been observed in the DMA studies.

\section{E. Microscopic Analysis}

The microscopic analysis was done by examining the fractured surfaces of the MWNT/GFRP nanocomposites to check the failure pattern. From the previous results of tensile, vibration damping, fatigue and dynamic mechanical tests it is evident that CNTs can be used as secondary reinforcements as functional fillers to enhance critical structural and material properties of GFRP composites. In general, GFRP composites hold high stiffness and fatigue strength, but they suffer from weak damping. CNTs as secondary reinforcements strengthen the primary reinforcements in micro or nano scale and enhances the damping without affecting the other parameters.

In the present microscopic analysis, the specimens: GFRP/NE, GFRP/R 0.5 and GFRP/A 0.5 were examined to emphasize more on the role of MWNT in enhancing the basic material properties. The fractured planes of the failure specimens examined in different view angles to study the interfacial behavior of the CNTs at the fiber and polymer interfaces by using scanning electron microscope (SEM). Field emission scanning electron microscopy (FESEM) was also

done for getting finer details of the fractured planes.

Fig. 9 (a) and 9(b) shows microscopic views of GFRP/NE. In Fig 9 (a), both horizontal and vertical fibers of different layers can be observed. Fig 9 (b) is the close view of GFRP/NE fractured specimen where the fractured plane is perpendicular to the loading axis.

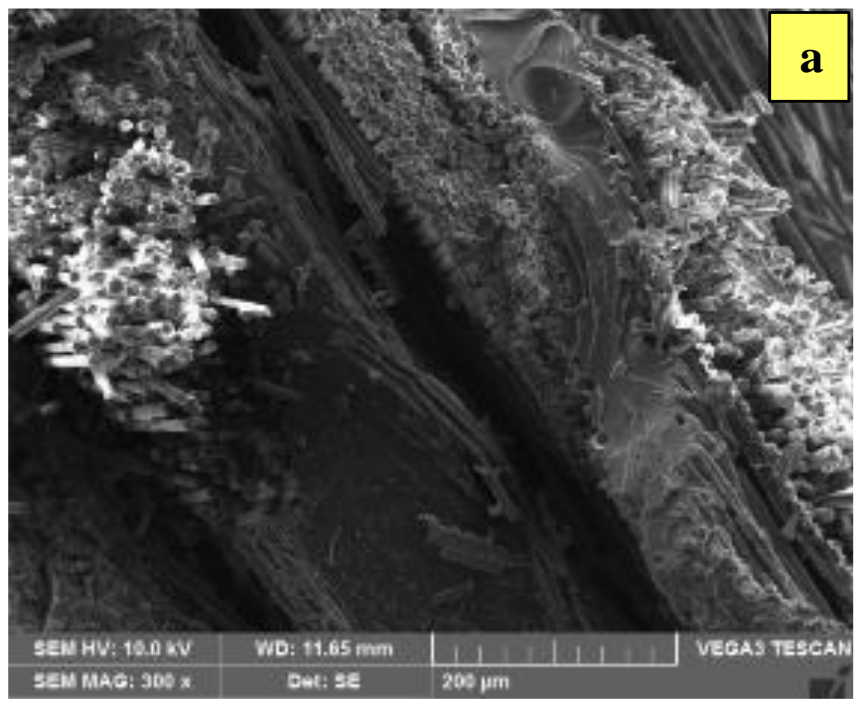

Fig 10 (a) shows the distribution of CNTs on glass fabric. The SEM image of GFRP/R 0.5 clearly showed a mixed trend of CNT distribution where some shiny objects are spotted like dots and long elements, and this indicates that the CNTs are distributed randomly in the GFRP composite. It is also observed that some fibers protruded from the fractured surface and small pits are found on its counterparts, which confirms the fiber pull-out failure mechanism. The fiber pullout mechanism directly relates the toughness and other properties of fiber reinforced composites. In fiber reinforced composites crack is developed or initiated at the surface of the composite specimen and it will propagate through the from the matrix, which are trying to bridge the gap created by the crack. Both fiber breaking and fiber pull-out mechanisms improves strength, fracture toughness, fatigue life and damping by delaying the crack propagation and final fracture. Fig 10 (b), (c) and (d) shows the fiber pull-out of GFRP nanocomposites.

Especially in the case of GFRP composites both fiber and epoxy matrix are brittle materials, the load carrying capabilities of fiber and interfacial bonding of fiber and matrix will be low. The addition of CNTs to the GFRP as secondary reinforcement not only strengthen the glass fibers, i.e., primary reinforcements but also enhances the interfacial bonding of fiber and the matrix which results in extended crack propagation time. Further, this effect can be still improved by aligning the CNTs in a specific direction, i.e., along with the loading axis which makes the fibers very strong.

As the CNTs are embedded in the epoxy matrix and coated on the GFRP fabric with very low wt.\% it is difficult to locate the CNTs through scanning electron microscope. FESEM analysis was also done to examine the microstructural behavior of CNTs in the GFRP composites. Fig. 11 shows the FESEM images of the fractured surfaces

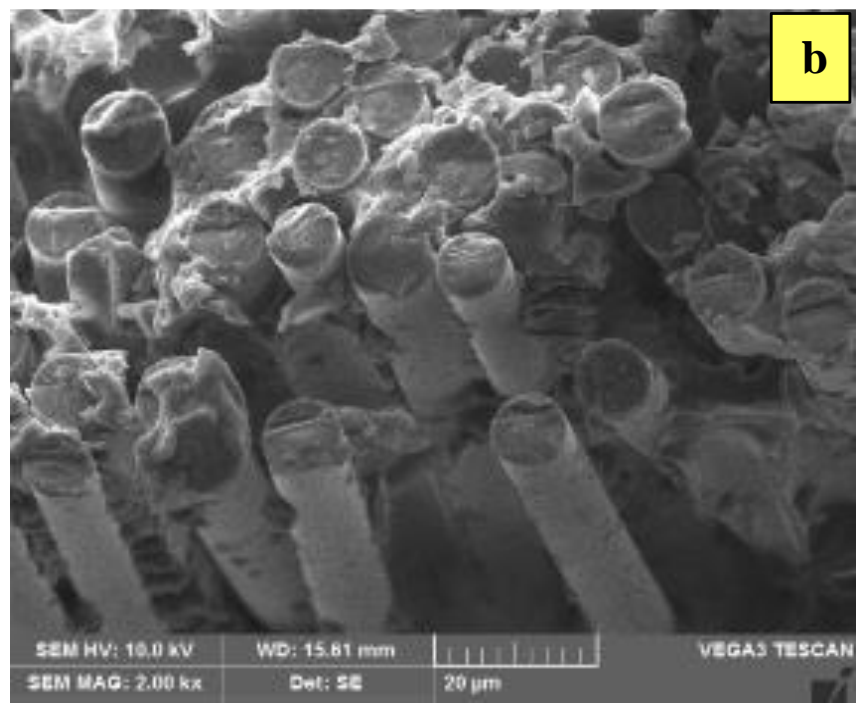

Fig. 9. Fractographic analysis of MWNT/GFRP nanocomposites: (a) fractured surface of GFRP/NE, (b) fractured surface of GFRP/A0.5 
Tensile, Fatigue and Vibration Damping Characteristics of High- Performance Glass Fiber Reinforced Composites with Aligned MWNTs
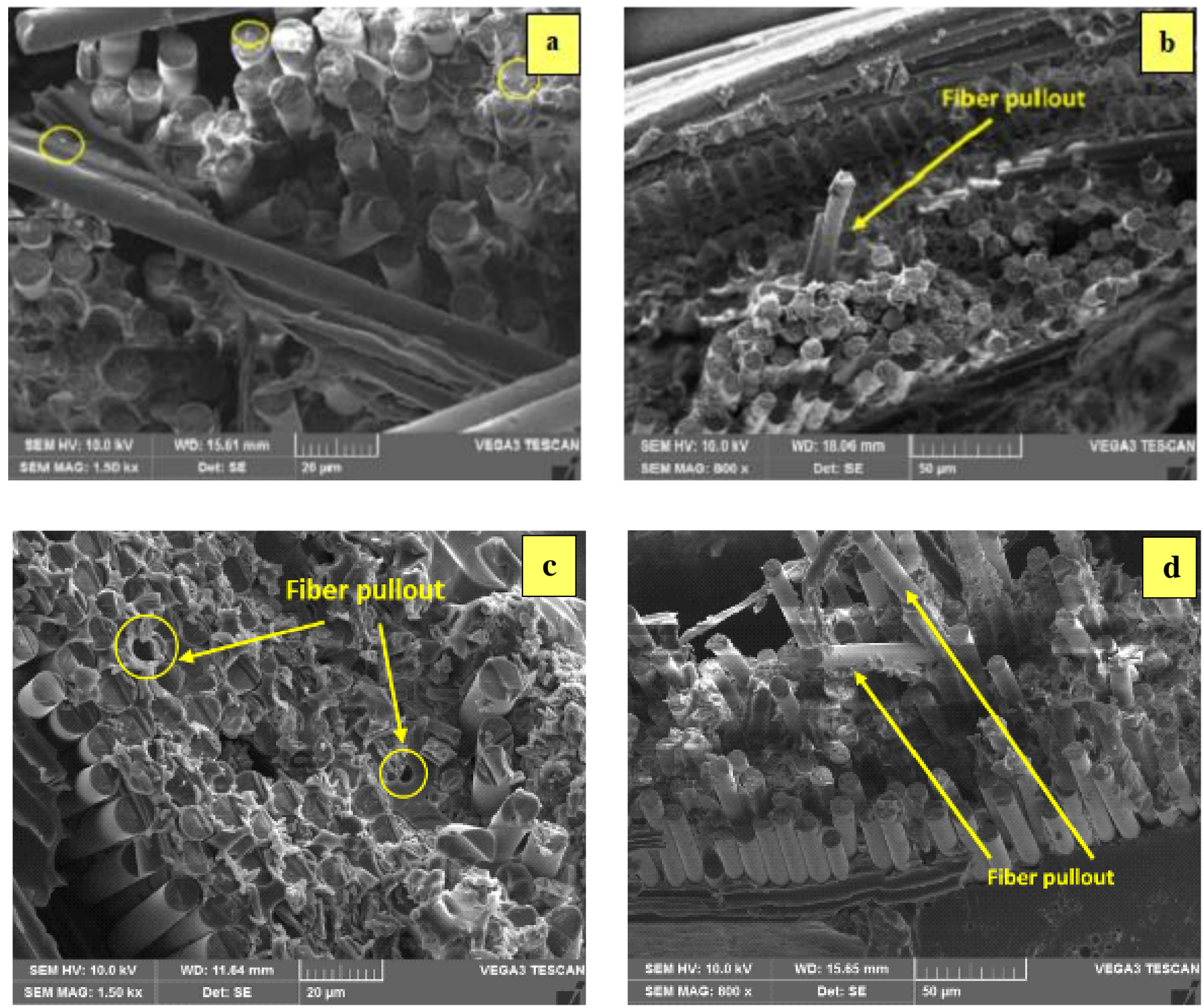

Fig. 10. SEM analysis of fiber pullout: (a) distribution of CNTs in GFRP/R 0.5, (b) fiber pull-out in GFRP/R 0.5, (c) fiber pull-out in GFRP/R 0.5 counterpart specimen, (d) fiber pull-out in GFRP/A 0.5
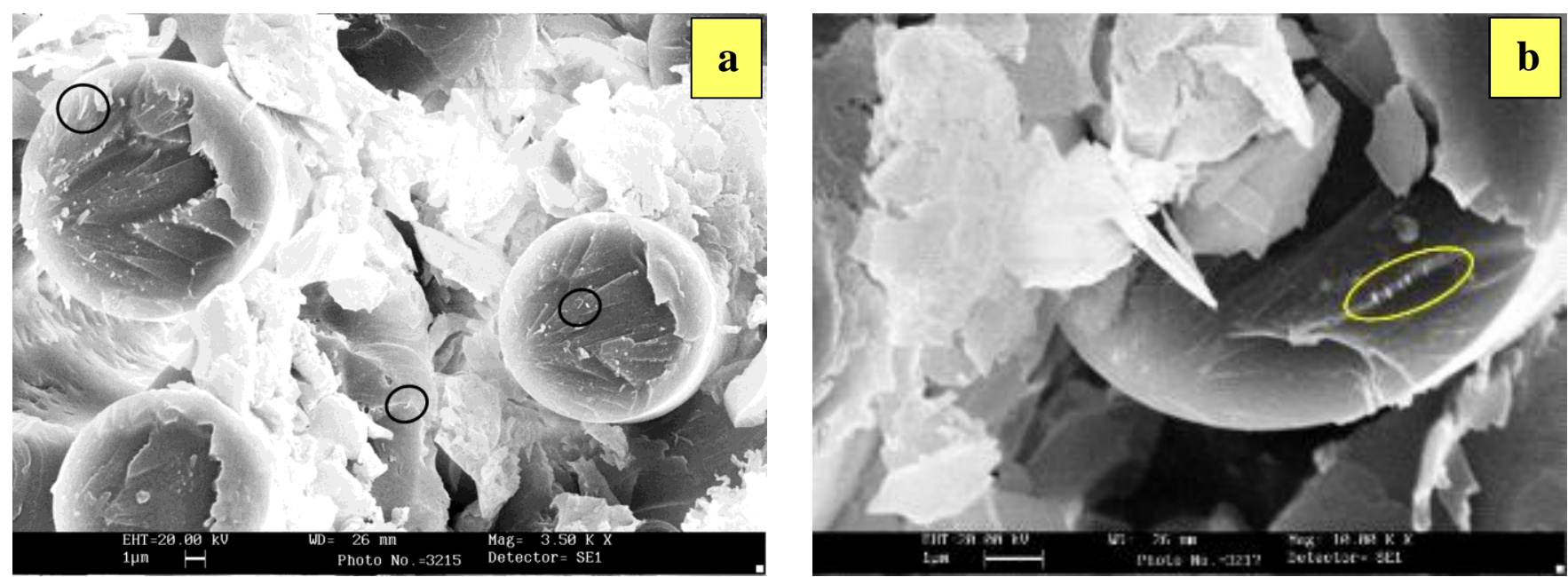

Fig. 11. FESEM analysis of MWNT/GFRP nanocomposites (a) MWNT network in GFRP/R 0.5, (b) MWNT network in GFRP/A 0.5

Retrieval Number: C5774029320/2020@BEIESP DOI: 10.35940/ijeat.C5774.029320

Journal Website: www.ijeat.org
Published By:

3000 Blue Eyes Intelligence Engineering \& Sciences Publication

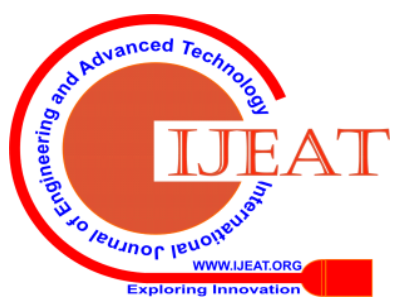




\section{RESULT AND DISCUSSION}

The current research has studied the effect of MWNTs alignment in glass fiber reinforced nanocomposites with low content of MWNTs (0.5 wt \%). The following results can be highlighted from the investigation:

1) The addition of MWNTs to the GFRP composites improved the tensile modulus. The random dispersion of MWNTs in the GFRP has shown nearly $10 \%$ improvement over neat GFRP. Whereas, for the same MWNT loading the aligned MWNTs in the GFRP has shown $26 \%$ over neat GFRP and $14 \%$ over GFRP with random networks.

2) There is a remarkable effect on ultimate tensile strain due to the MWNTs inclusion and alignment, which further enhances the toughness (area under the stress-strain curve) of both random and aligned networks over the neat GFRP. This indicates that the inclusion and the alignment of MWNTs have significant improvement in enhancing the stiffness and toughness of glass fiber reinforced nanocomposites.

3) The MWNTs are favorable for enhancing the fatigue life provided with proper dispersion. The alignment of MWNTs in GFRP has a moderate improvement (7\%) over neat GFRP and marginal improvement $(0.5 \%)$ over random networks.

4) The presence of MWNTs in GFRPs has shown noticeable improvement in damping, but the improvement was moderate for random MWNT networks and significant for aligned MWNT networks.

5) The addition of MWNTs favors the improvement of damping (structural) capabilities moderately without changing the natural frequency. Further, the MWNTs with specified orientation have shown marginal improvement (5\%) over random networks; however, the improvement was significant (11\%) when compared with neat GFRP.

\section{CONCLUSION}

CNTs are highly anisotropic at the particle level but not in the bulk form mainly due to the agglomeration and random orientation. Dispersion and alignment of CNTs is the only solution to transfer the particle level high anisotropy to the bulk nanocomposites. Nevertheless, the resulting properties of nanocomposite depends on various parameters like CNT loading weight percentage, quality of dispersion and the alignment technique adopted. In this research, the alignment of CNTs on glass fiber laminae has done using a parallel electrodes connected to DC electric field. The addition of MWNTs to the glass fiber reinforced composites as secondary reinforcement at very low weight percentage $(0.5$ wt\%) has distinct improvement in nanocomposites vibrational damping without compromising its critical mechanical properties further this effect will be significant by orienting the MWNTs in the preferred direction which not only enhances the vibrational damping and mechanical properties but also the directional properties of nanocomposites.

\section{ACKNOWLEDGMENT}

The authors would like to acknowledge the financial support received from the Government of India under the 12th Five Year Plan of Council of Scientific and Industrial Research, India (Project No. ESC-02-12-02). Authors specially acknowledge Jerald Maria Antony, Vijay Kumar M P, Mahesh M, Veda Prakash S, and Nagaraj K of Structural Technologies Division, CSIR-NAL, for their technical help during fabrication, testing, and characterization. The authors express their appreciation to the following students who helped us in this research work: Hema Devi A, Karthik Periswamy.

\section{REFERENCES}

1. C. S. G. AE. C. K. H. Dharan, "High-cycle fatigue of hybrid carbon nanotube / glass fiber / polymer composites," J. Mater. Sci., vol. 43, pp. 4487-4492, 2008.

2. S. Ct and C. Ws, "Frequency Effect on the Fatigue Life of a Laminated Composite," ASTM STP, vol. 674, pp. 418-430, 1979.

3. L. P. Borrego, J. D. M. Costa, J. A. M. Ferreira, and H. Silva, "Fatigue behaviour of glass fibre reinforced epoxy composites enhanced with nanoparticles," Compos. Part B, vol. 62, pp. 65-72, 2014.

4. D. R. Bortz, C. Merino, and I. Martin-gullon, "Carbon nanofibers enhance the fracture toughness and fatigue performance of a structural epoxy system," Compos. Sci. Technol., vol. 71, pp. 31-38, 2011

5. S. Helmy and S. V Hoa, "Tensile fatigue behavior of tapered glass fiber reinforced epoxy composites containing nanoclay," Compos. Sci. Technol., vol. 102, pp. 10-19, 2014.

6. M. Jf and U. Meier, "Effects of Stress Ratio, Frequency, and Loading Time on the Tensile Fatigue of Glass-Reinforced Epoxy," ASTM STP, vol. 813, pp. 55-77, 1983.

7. S. U. Khan, C. Y. Li, N. A. Siddiqui, and J. Kim, "Vibration damping characteristics of carbon fiber-reinforced composites containing multi-walled carbon nanotubes," Compos. Sci. Technol., vol. 71, no. 12, pp. 1486-1494, 2011.

8. H. Rajoria and N. Jalili, "Passive vibration damping enhancement using carbon nanotube-epoxy reinforced composites," Compos. Sci. Technol., vol. 65, pp. 2079-2093, 2005.

9. X. Zhou, E. Shin, K. W. Wang, and C. E. Bakis, "Interfacial damping characteristics of carbon nanotube-based composites," Compos. Sci. Technol., vol. 64, pp. 2425-2437, 2004.

10. S. Jangam, A. Hema Devi, S. Raja, K. Hemachandra Reddy, and G. Vijay Kumar, "The Tensile Fatigue Behaviour of Aligned MWNT/Epoxy Nanocomposites," in Proceedings of Fatigue, Durability and Fracture Mechanics, 2018, pp. 351-359.

11. C. M. Manjunatha, a. C. Taylor, a. J. Kinloch, and S. Sprenger, "The cyclic-fatigue behaviour of an epoxy polymer modified with micron-rubber and nano-silica particles,” J. Mater. Sci., vol. 44, pp 4487-4490, 2009.

12. S. Iijima, "Helical microtubules of graphitic carbon," Lett. to Nat., vol. 354, pp. 56-58, 1991.

13. S. Jangam, S. Raja, and B. U. Maheswar Gowd, "Influence of multiwall carbon nanotube alignment on vibration damping of nanocomposites," J. Reinf. Plast. Compos., vol. 35, no. 8, pp. 617-627, Apr. 2016.

14. S. Jangam, S. Raja, and K. H. Reddy, "Effect of multiwalled carbon nanotube alignment on the tensile fatigue behavior of nanocomposites," J. Compos. Mater., vol. 52, no. 17, pp. 2365-2374, Dec. 2017.

15. R. F. Gibson, E. O. Ayorinde, and Y.-F. Wen, "Vibrations of carbon nanotubes and their composites: A review," Compos. Sci. Technol., vol. 67, pp. 1-28, 2007.

16. C. M. Manjunatha, S. Sprenger, a. C. Taylor, and a. J. Kinloch, "The Tensile Fatigue Behavior of a Glass-fiber Reinforced Plastic Composite Using a Hybrid-toughened Epoxy Matrix," J. Reinf. Plast. Compos., vol. 0, no. 0, pp. 1-14, 2010.

17. S. Jangam, K. H. Reddy, and S. Raja, "Fabrication \& Characterization of Hybrid fibers and Hybrid Fiber reinforced composites - A Novel Approach," Mater. Today Proc., vol. 5, no. 1, pp. 2795-2802, 2018. 


\section{AUTHORS PROFILE}

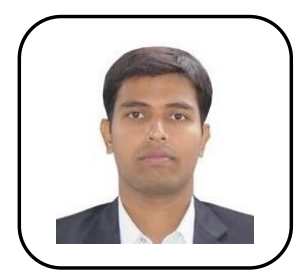

Dr. Sasidhar Jangam, currently working as an Assistant Professor in the department of Mechanical Engineering, School of Engineering and Technology, CHRIST University has obtained his B.Tech., degree in Mechanical Engineering from Jawaharlal Nehru Technological University, M.Tech., in Stress and Vibrations., from MANIT, Bhopal and PhD in Vibrations of Nanocomposites from Jawaharlal Nehru Technological University. He has authored 6 research articles and 2 book chapters and is a recipient of several awards and accolades for his outstanding work in the domain of material characterization. He is also regarded as a good professor and has developed teaching pedagogy and methodologies for content delivery in subjects of Design of machine elements, Mechanical Vibrations, Noise Vibration and Harshness, Finite Element Methods etc. He is a member of several technical societies and is actively involved in disseminating scientific principles and knowledge.

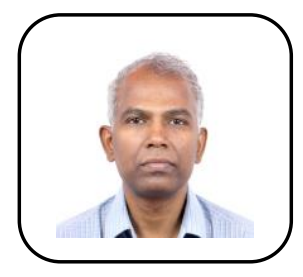

Dr. S. Raja, currently working as senior principal scientist and Head of Structural Technologies Division, CSIR-National Aerospace Laboratories (NAL), Bangalore has obtained his B.E., degree in Civil Engineering from Kamaraj University, Madurai, M.Tech., in Aerospace Engineering, from IIT Bombay, Ph.D., in Aerospace Engineering, from IIT Kharagpur and Post-Doctoral Fellowship from Nagoya University, Japan. He has to his credit more than 70 research articles published in Scopus indexed journals of very high impact factor and most of them belonging to Elsevier and Springer Publications. He has authored several books and chapters and is a recipient of several national and international awards and accolades for his outstanding work in the domain Aeroelasticity. He has total citations of 922 and h-index: 17. He is a member of several technical societies and is actively involved in disseminating scientific principles and knowledge.

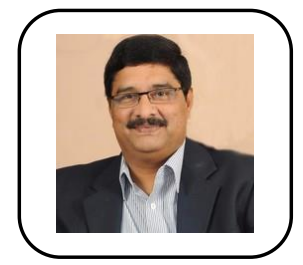

Dr. k. Hemachandra Reddy, currently working chairman of APSCHE and professor of Jawaharlal Nehru Technological University, Anantapuramu has obtained his B.Tech., degree in Mechanical Engineering from Jawaharlal Nehru Technological University, M.E., and Ph.D., in Thermal engineering from Jawaharlal Nehru Technological University. He has to his credit more than 150 research articles published in Scopus indexed journals of very high impact factor and most of them belonging to Elsevier and Springer Publications. He has total citations 1824 and h-index: 21He has authored several books and chapters and is a recipient of several awards and accolades for his outstanding work in the domain of thermal and materials research. He is also regarded as a good professor and has developed teaching pedagogy and methodologies for content delivery in subjects of Materials Science, Thermodynamics, Thermal engineering, Refrigeration and Airconditioning. He is a member of several technical societies and is actively involved in disseminating scientific principles and knowledge.

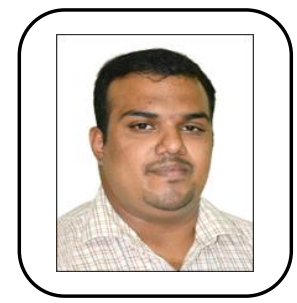

Dr. Shijjo Thomas, currently working as an Assistant Professor in the department of Mechanical Engineering, School of Engineering and Technology, CHRIST University has obtained his B.E., and M.E., in Mechanical Engineering from Anna University, MBA., from Bharathiar University, and $\mathrm{PhD}$ in Composite Technology from VIT-Vellore. He has authored 10 research articles and 3 book chapters and is a recipient of several awards and accolades for his outstanding work in the domain of material research. He is a member of several technical societies and is actively involved in disseminating scientific principles and knowledge. 